\title{
In Vivo Targeting of the Neurovascular Unit: Challenges and Advancements
}

\author{
Oandy Naranjo ${ }^{1} \cdot$ Olivia Osborne $^{1} \cdot$ Silvia Torices $^{1} \cdot$ Michal Toborek $^{1,2,3}$ (D)
}

Received: 11 February 2021 / Accepted: 28 May 2021 / Published online: 4 June 2021

(c) The Author(s) 2021

\begin{abstract}
The blood-brain barrier (BBB) is essential for the homeostasis of the central nervous system (CNS). Functions of the BBB are performed by the neurovascular unit (NVU), which consists of endothelial cells, pericytes, astrocytes, microglia, basement membrane, and neurons. NVU cells interact closely and together are responsible for neurovascular coupling, BBB integrity, and transendothelial fluid transport. Studies have shown that NVU dysfunction is implicated in several acute and chronic neurological diseases, including Alzheimer's disease, multiple sclerosis, and stroke. The mechanisms of NVU disruption remain poorly understood, partially due to difficulties in selective targeting of NVU cells. In this review, we discuss the relative merits of available protein markers and drivers of the NVU along with recent advancements that have been made in the field to increase efficiency and specificity of NVU research.
\end{abstract}

Keywords Neurovascular unit $\cdot$ Imaging $\cdot$ Protein expression $\cdot$ Cre mouse models $\cdot$ Blood-brain barrier

\section{Introduction}

Communication between the cells of the neurovascular unit (NVU) that create and maintain the framework of the blood-brain barrier (BBB) is critical to the homeostasis and proper function of the central nervous system (CNS). Endothelial cells, pericytes, astrocytic end feet, and microglia closely interact with each other to form the basis of the NVU and the BBB. Their communicative signals act in concert to ensure proper regulation. For example, endothelial cells rely on vitronectin and angiopoietin I from pericytes, and Sonic Hedgehog from astrocytes (Hill et al. 2019). While all three of these ligands function through different pathways, their mutual cascade results in endothelial cell survival and BBB maintenance. In return, endothelial cells

Michal Toborek

mtoborek@med.miami.edu

1 Department of Biochemistry and Molecular Biology, University of Miami Miller School of Medicine, Miami, FL 33136, USA

2 Institute of Physiotherapy and Health Sciences, The Jerzy Kukuczka Academy of Physical Education, Katowice, Poland

3 Department of Biochemistry and Molecular Biology, University of Miami School of Medicine, Gautier Bldg., Room 528, 1011 NW 15th Street, Miami, FL 33136, USA secrete platelet-derived growth factor-beta (PDGF- $\beta$ ), which provides reciprocal survival signals to pericytes through protein kinase B and stimulates further vitronectin production (Chatterjee and Naik 2012). Astrocytes of the NVU express angiotensin II, which contributes to vessel stability through modulation of occludin tight junctions, an essential protein for BBB permeability (Wosik et al. 2007). Lastly, astrocytes are critical to the microenvironment of the NVU, controlling ion and water concentrations through aquaporin 4 on the cell membranes of astrocytic endfeet that interact with endothelial cells (Abbott et al. 2006) (Fig. 1). While communication between these cells is essential, certain neurological pathologies can induce signal attenuation via BBB breakdown.

Common neuropathologies that are induced by BBB breakdown and subsequent NVU signaling disruption include Alzheimer's disease (AD), multiple sclerosis (MS), and stroke. Disruption of NVU stability leads to dysfunction of the BBB which has been increasingly linked to pathobiology of neurocognitive disorders, CNS infections, and toxicity of substance abuse (Bertrand et al. 2019a, b; Castro et al. 2016; Cho et al. 2017; Daneman et al. 2010; Kisler et al. 2020; Lee et al. 2001; Mathiisen et al. 2010; Nakagawa et al. 2012; Zlokovic 2008). For example, the breakdown of the $\mathrm{BBB}$ is a central factor to the onset and progression of AD (Zlokovic 2010). One of the leading hypotheses in AD research is that pathological 
Fig. 1 Crosstalk at the neurovascular unit. A schematic diagram illustrating selective interactions between endothelial cells, pericytes, and astrocytes that maintain the blood brain barrier (BBB). The cells of the neurovascular unit provide the mature endothelium with the survival signals required for maintaining the functional BBB. Pericytes secrete angiopoietin I and vitronectin which maintain healthy endothelial cells. Endothelial cells secrete platelet-derived growth factor-beta that maintain survival of pericytes. Astrocytes secrete Sonic Hedgehog which functions through the patched receptor and lead to survival signals in endothelial cells. Astrocytes also control the BBB microenvironment and permeability. Through angiotensin II expression, astrocytes influence occludin expression in tight junctions and barrier properties. Lastly, astrocytes can change ionic concentrations through the water and potassium channels, such as aquaporin 4 and ATP-sensitive inward rectifier potassium channel 10

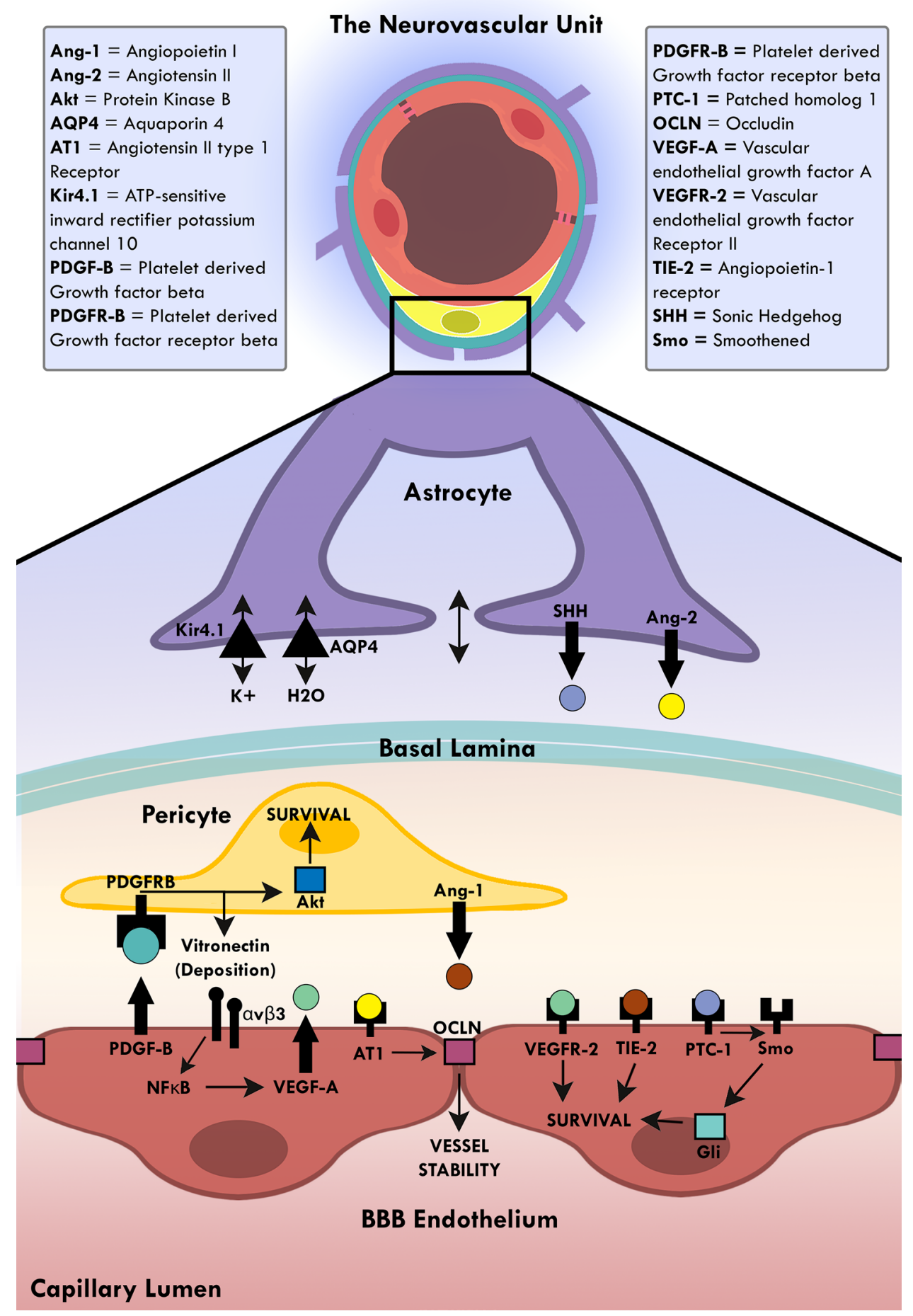

accumulation of beta-amyloid ( $\mathrm{A} \beta$ ) leads to plaque formation over time. A $\beta$ plaque deposits in both the brain parenchyma and cerebral blood vessels lead to various vessel pathologies including decreased cerebral blood flow and BBB breakdown (Merlini et al. 2011). Research has shown that activation of both microglia and astrocytes are critical to $\mathrm{AD}$ pathology and both cell types play a role in $\mathrm{A} \beta$ protein concentration and clearance, respectively (Fuhrmann et al. 2010; Liu et al. 2010; Merlini et al. 2011). Moreover, a loss of capillary pericytes is observed in the white matter of AD patients and other common dementias (Ding et al. 2014). Therefore, identifying specific markers for 
these cell types may aid in rapid diagnostic, provide tools for better understanding of the disease process as well as therapeutic assessments of $\mathrm{AD}$ patients.

MS is a neuroinflammatory disease whereby resident and infiltrating immune cells form lesions in the white matter of the CNS that lead to demyelinating plaques (Lassmann 2010). Evidence suggests that BBB disruption through endothelial cell dysfunction and the release of inflammatory cytokines is observed early on in disease progression (Correale et al. 2017; Minagar and Alexander 2003). T cells, microglia, monocytes, and fibrinogen proteins all contribute to the neuroinflammation observed (Adams et al. 2007; Ajami et al. 2011; Heppner et al. 2005). While the progression of the disease is still poorly understood, evidence suggests that targeting the cells of the NVU is critical for a mechanistic understanding of MS and how to treat it. For instance, attenuating BBB dysfunction through endothelial $w n t / \beta$-catenin signaling reduces immune cell infiltration and improves neurological condition (Lengfeld et al. 2017). Retinoic acid expression in pericytes was found to modulate the endothelial wnt $/ \beta$-catenin signaling pathway (Lai et al. 2003), which offers a potential target for MS therapy. By utilizing NVU markers, we can better characterize the breakdown of the BBB that leads to CNS infiltration by immune cells, providing potential new therapeutic targets.

Similarly, one of the hallmarks of ischemic stroke pathology is the breakdown of cerebrovasculature and the BBB, which increases paracellular permeability. Despite better treatments, imaging techniques, and understanding of strokeassociated risk factors, diagnosis of acute stroke remains difficult (Arch et al. 2016). In actuality, studies show that about $25 \%$ of ischemic stroke patients are difficult or impossible to diagnose, therefore novel strategies are needed to diagnose within a therapeutic window (Amarenco et al. 2009). Given the small therapeutic window of ischemic stroke, timely diagnosis can significantly improve post-stroke outcomes and lower stroke mortality (Jahan et al. 2019). Recent work in the cerebrovascular field shows that biomarker panels rather than a single marker can be an effective approach to stroke diagnosis; however, their clinical accuracy has yet to be confirmed (Jickling and Sharp 2015). In order to assess marker levels, we must understand the signaling pathway progression during ischemic onset, and more specifically, the cells of the NVU that secrete distinct signals during acute, subacute, and late phases of stroke (Steliga et al. 2020). Therefore, diagnostic markers for BBB dysfunction that can efficiently target NVU cells at different timepoints may be critical to identify stage-specific biomarkers and understand the changes in intercellular communication within the NVU during brain pathologies.

Progress on the NVU involvement in neuropathology has been hampered due to lack of specific imaging and targeting techniques as well as heterogeneity within NVU cell populations (Smyth et al. 2018; Yoon et al. 2017). Moreover, targeting techniques within live systems are exceedingly difficult. The main challenge not only lies in identifying NVU markers for the generation of in vivo models, but also the ability and limitations in linking the marker etiologies during cerebral abnormalities to pathophysiology and histopathology. While there has been a growing list of drivers and markers for NVU cells, they frequently lack full specificity, resulting in cross reactivity with other cells. However, even semi-specific markers can be a powerful tool for NVU experiments if the limitations are understood when interpreting the data. Likewise, work has been done to produce novel Cre genetic mouse models and drive expression of specific proteins in the cells of the NVU. This review discusses current standard markers of NVU cells and their pitfalls, along with the new advancements in the field that aid in the design of mechanistic in vivo studies evaluating the involvement of the NVU in the pathobiology of neurological diseases.

\section{Endothelial Cells}

Endothelial cells originate from mesoderm and line blood and lymphatic vessels throughout the body (Bautch and Caron 2015). They constitute the main cellular element of the BBB by forming tight junctions that link endothelial cells together and form a selectively permeable barrier between the blood and the CNS. Ultimately, the BBB maintains the homeostasis of the CNS and prevents toxic molecules, viruses, bacteria, and inflammatory cells from reaching the brain (Bernacki et al. 2008; Daneman and Prat 2015). Visualizing endothelial cells is crucial to understanding how different experimental conditions can affect BBB permeability.

CD31, CD34, and CD54 are all standard markers for the vascular endothelium (Table 1), but they lack full selectivity as they are also expressed in other cell types (Pusztaszeri et al. 2006). For example, CD31, known as platelet/endothelial cell adhesion molecule 1 (PECAM-1), is also expressed in B cells, platelets, macrophages, monocytes, NK cells, and $\mathrm{T}$ cells (Nourshargh et al. 2006). CD34 expresses cross reactivity with dendritic cells, hematopoietic stem cells, leukemic cells, and endothelial progenitor cells (Sidney et al. 2014). In addition to endothelial cells, CD54, known as intercellular adhesion molecule 1 (ICAM-1), is expressed in lymphocytes and macrophages (Dustin et al. 2011). Nevertheless, even with significant cross reactivity, CD31, CD34, and CD54 can serve as effective markers in immunostaining studies because endothelial vasculature is visually different from other cell types. VE-cadherin, known also as Cadherin 5 (Cdh5), is another effective marker for vascular endothelium. Cdh5 protein is found at endothelial cell 
Table 1 Cell markers of the neurovascular unit

\begin{tabular}{|c|c|}
\hline \multicolumn{2}{|l|}{ Endothelial cells } \\
\hline Marker & Non-endothelial expression \\
\hline CD31/PECAM-1 & B cells, platelets, macrophages, monocytes, natural killer cells, and T cells \\
\hline CD34 & Dendritic cells, hematopoietic stem cells, leukemic cells, and endothelial progenitor cells \\
\hline CD54/ICAM-1 & Lymphocytes and macrophages \\
\hline VE-Cadherin/Cdh5 & Hematopoietic and mesenchymal stem cells \\
\hline Lectin & No reported expression \\
\hline Tie-2 & Subset of macrophages \\
\hline CD106/VCAM-1 & $\begin{array}{l}\text { Tissue macrophages, dendritic cells, bone marrow fibroblasts, myoblasts, oocytes, } \\
\text { Kupffer cells, and Sertoli cells }\end{array}$ \\
\hline \multicolumn{2}{|l|}{ Pericytes } \\
\hline Marker & Non-pericyte expression \\
\hline PDGFR $\beta$ & Neural progenitor cells, glia, and fibroblast cells during injury \\
\hline CD13 & Cells of myeloid origin \\
\hline NG2/Cspg4 & Oligodendrocyte progenitors, Schwann cells, and perineurial cells \\
\hline CD146 & Immature endothelial cells, ganglion cells and activated $\mathrm{T}$ lymphocytes \\
\hline Nestin & Progenitor cells \\
\hline NeuroTrace 500/525 & No reported expression \\
\hline \multicolumn{2}{|l|}{ Astrocytes } \\
\hline Marker & Non-astrocyte expression \\
\hline GFAP & $\begin{array}{l}\text { Progenitor cells, fibroblasts, enteric glia, satellite cells, Schwann cells, chondrocytes, } \\
\text { myoepithelial cells, and lymphocytes }\end{array}$ \\
\hline ALDH1L1 & Neural stem cells \\
\hline EAAT1/GLAST1 & Microglia and oligodendrocytes \\
\hline EAAT2/GLAST2 & Microglia and oligodendrocytes \\
\hline AQP4 & Microglia \\
\hline S100 $\beta$ & Oligodendrocytes, oligodendrocyte progenitor cells, and microglia \\
\hline Aldolase C & Neurons \\
\hline \multicolumn{2}{|l|}{ Microglia } \\
\hline Marker & Non-microglial expression \\
\hline CD11b & $\begin{array}{l}\text { Monocytes, neutrophils, natural killer cells, granulocytes, macrophages, red blood cells, } \\
\text { and memory B cells }\end{array}$ \\
\hline Iba1 & Macrophages, vascular smooth muscle cells, and neutrophils \\
\hline CX3CR1 & Monocytes, natural killer cells, circulating and skin resident dendritic cells, CD8+ T cells \\
\hline CD45 & All differentiated hematopoietic cells \\
\hline Tmem119 & Oligodendrocyte precursor cells \\
\hline P2RY12 & Granulocytes and Kupffer cells \\
\hline FCRLS & Kupffer cells, Ileal macrophages, oligodendrocyte precursor cell, embryonic fibroblast \\
\hline HexB & Hoffbauer cells and Kupffer cells \\
\hline
\end{tabular}

junctions where it plays a critical role in endothelial barrier function and angiogenesis (Dejana et al. 2009). Cdh5 is specific for endothelial cells at the NVU; however, it can also be expressed on hematopoietic stem cells and mesenchymal stem cells (Vestweber 2008).

A marker with very high specificity for the vascular endothelium is Lycopersicon esculentum (Tomato) lectin
(LEL) (Mazzetti et al. 2004; Smolkova et al. 2001). Lectins conjugated to different dyes are commercially available and can be employed to visualize vasculature using intravascular perfusion methods or direct application to tissue sections (Nikolakopoulou et al. 2017; Robertson et al. 2015). LEL binds to sugars enriched on the basement membrane of endothelial cells in human and rodent samples (Piller 
et al. 1990). The advantages of LEL are that it does not depend on primary and secondary species-specific antibody interactions. Angiopoietin-1 receptor (TIE-2) is a surface receptor that regulates angiogenesis and cell survival. TIE-2 is expressed in both young and adult endothelial cells but also on a subset of angiogenic promoting macrophages (De Palma et al. 2005). In the neurovascular unit, TIE-2 is very specific to endothelial cells and can be used as a target for endothelial visualization (Fukuhara et al. 2009; Sato et al. 1995). Lastly, vascular cell adhesion protein 1 (VCAM-1/ CD106) can modulate BBB endothelium to increase permeability to immune cells and is activated upon proinflammatory stimulation (Haarmann et al. 2015). VCAM-1 can be used as a marker to visualize injury and inflammation in endothelial cells of the BBB; however, it is also expressed by tissue macrophages, dendritic cells, bone marrow fibroblasts, myoblasts, oocytes, Kupffer cells, and Sertoli cells (Kong et al. 2018; Osborn et al. 1989).

\section{Drivers for Endothelial Cell Expression}

Cre recombinase mouse models are a powerful tool for targeted protein expression. Constitutive and inducible Cre models are based on a cell specific promoter driving Cre expression. CreERT2 encoding a Cre recombinase (Cre) fused to a mutant estrogen ligand-binding domain (ERT2) is a widely used Cre-ER version, which has low background Cre activity and robust activation following tamoxifen treatment (Table 2). Tek-Cre (Tie2-Cre) was the first endothelial specific Cre mouse model and still the most commonly used (Payne et al. 2018). Tie-2 Cre models are characterized by constitutive expression in all endothelial cells starting from early development and continuing into adulthood. Because Tie-2 is expressed by a precursor of both blood and endothelial lineage, Cre recombinase activity in Tie-2 Cre models are also present in cells of hematopoietic lineage (Kisanuki et al. 2001; Tang et al. 2010).

VE Cadherin/Cadherin 5 (Cdh5-Cre/ERT2) is frequently employed as an inducible driver that is specific for endothelial cells. Cdh5-Cre/ERT2 uses three Cadherin 5 alleles in the Cdh5 locus to drive Cre/ERT2 expression (Monvoisin et al. 2006; Okabe et al. 2014; Wang et al. 2010). More specifically, the $\operatorname{Tg}(\mathrm{Cdh} 5 \text {-cre/ERT2 })^{1 \text { Rha }}$ allele has been published for pan-endothelial expression in retina and brain endothelium of post-natal mice (Wang et al. 2010; Yanagida et al. 2017). Two alleles, $\operatorname{Tg}(\mathrm{Cdh} 5 \text {-cre/ERT2 })^{\# \text { Ykub and }}$ $\mathrm{Tg}(\mathrm{Cdh} 5 \text {-cre/ERT2 })^{\mathrm{CIVE} 23 \mathrm{Mlia}}$, have been well characterized in pre-natal mice. One aspect of Cre recombinase models to note is their potential for experimental variability in recombination efficiency. Variability in the Cdh5 inducible allele expression has been reported with identical tamoxifen doses and between different floxed alleles within the same mouse (Zarkada et al. 2015). This variability, given the same amount of tamoxifen, poses as a potential weakness in the model system and should be accounted for.

Figure 2 provides examples of generating mice expressing GFP in the vascular endothelium using CD31 as endothelial cell driver. In this model, CD31 drives Cre recombinase then excises the stop codon flanked by loxP sequences. With no stop codon, GFP can be expressed in any cell with CD31 activity (Fig. 2A). An inducible Cre model can be achieved by fusing Cre recombinase with a ligand-binding domain of the human estrogen receptor (ER) as a transgene, resulting in tamoxifen-dependent Cre recombinase. Under these conditions GFP is expressed in CD31 positive cells until the animal receives a tamoxifen regimen, upon which tamoxifen metabolite 4-hydroxytamoxifen (4-OHT) activates ER (Fig. 2B).

\section{Brain Pericytes}

Brain pericytes are mural cells that cover brain capillaries and venules with their cytoplasmic processes close to $100 \%$. Pericytes are highly heterogeneous, which may reflect their origin that varies in different parts of the body and even in various regions of the brain. While pericytes in the forebrain are derived from neural crest cells, pericytes in the rest of the brain appear to originate from mesenchymal stem cells of the mesoderm (Zheng et al. 2020). Moreover, recent evidence indicates that myeloid progenitors also contribute to the developing of pericytes in the brain. In fact, it was proposed that a substantial pool of brain pericytes originate from yolk-sac-derived macrophage progenitors (Yamazaki et al. 2017). Developmentally, pericyte recruitment to CNS vessels (E11 in rat cerebral cortex) correlates with the onset of barrier properties of the BBB (Daneman et al. 2010). They are the only cell in the NVU to have direct contact with BBB endothelium as part of pericyte-endothelium interface, called peg-socket contacts, that lacks a basement membrane. Pericytes are responsible for regulation of paracellular/transendothelial fluid transport, homeostasis of the microenvironment, and protecting endothelial cells from toxic substances (Armulik et al. 2011; Daneman et al. 2010; Nikolakopoulou et al. 2019).

Interestingly, pericytes remain a relatively poorly defined cell type due to the lack of highly specific cell markers. The difficulty of targeting this cell type due to their heterogeneity. In addition, their marker expression depends on anatomical location and function (Attwell et al. 2016). Because there is no pan-pericyte specific cell marker, morphology and a combination of at least two cell markers are necessary to identify pericytes in the brain (Smyth et al. 2018). Platelet-derived growth factor receptor- $\beta$ (PDGFRß) (Table 1 ) is the most commonly 


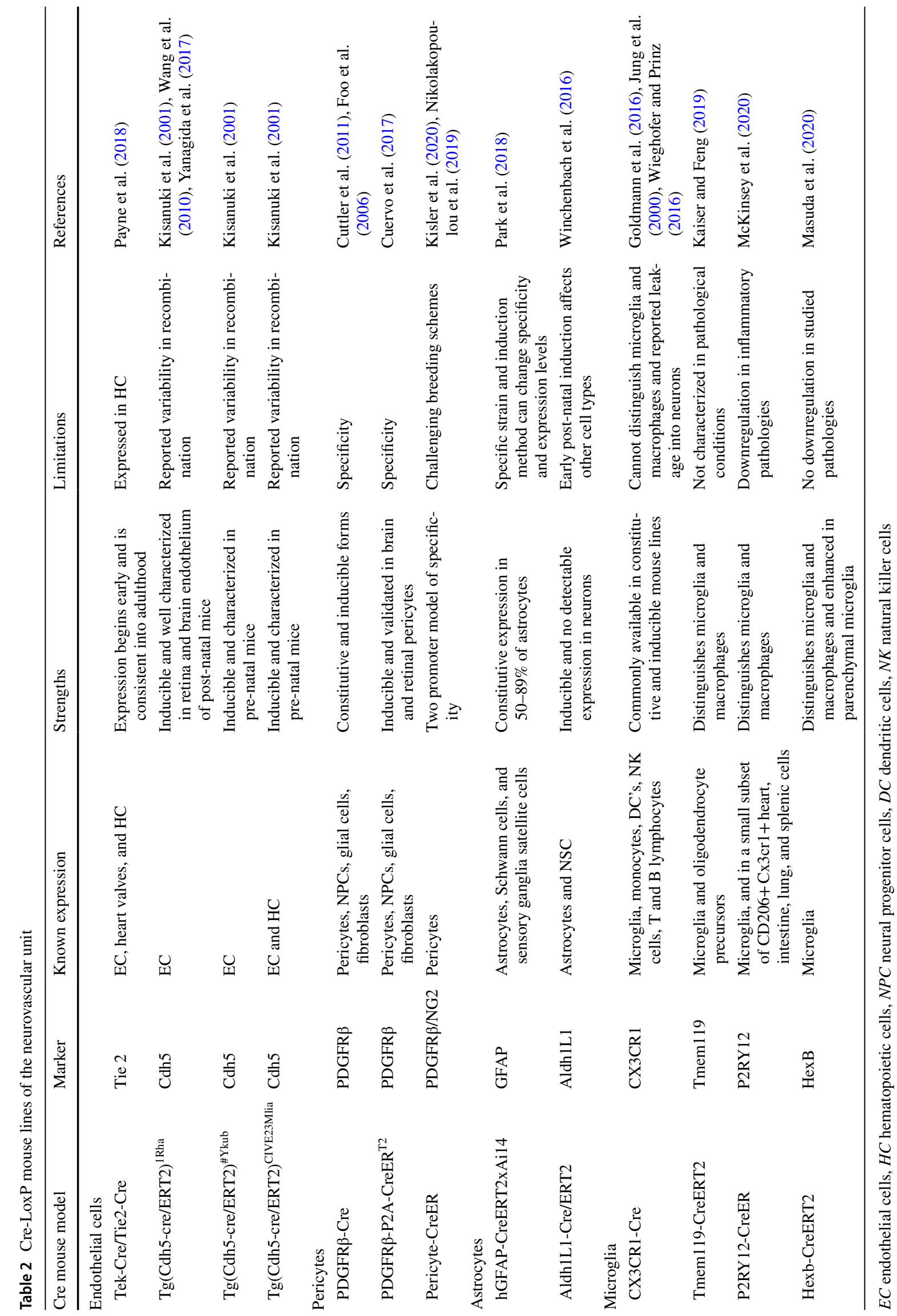




\section{A Non-Inducible Cre Line}

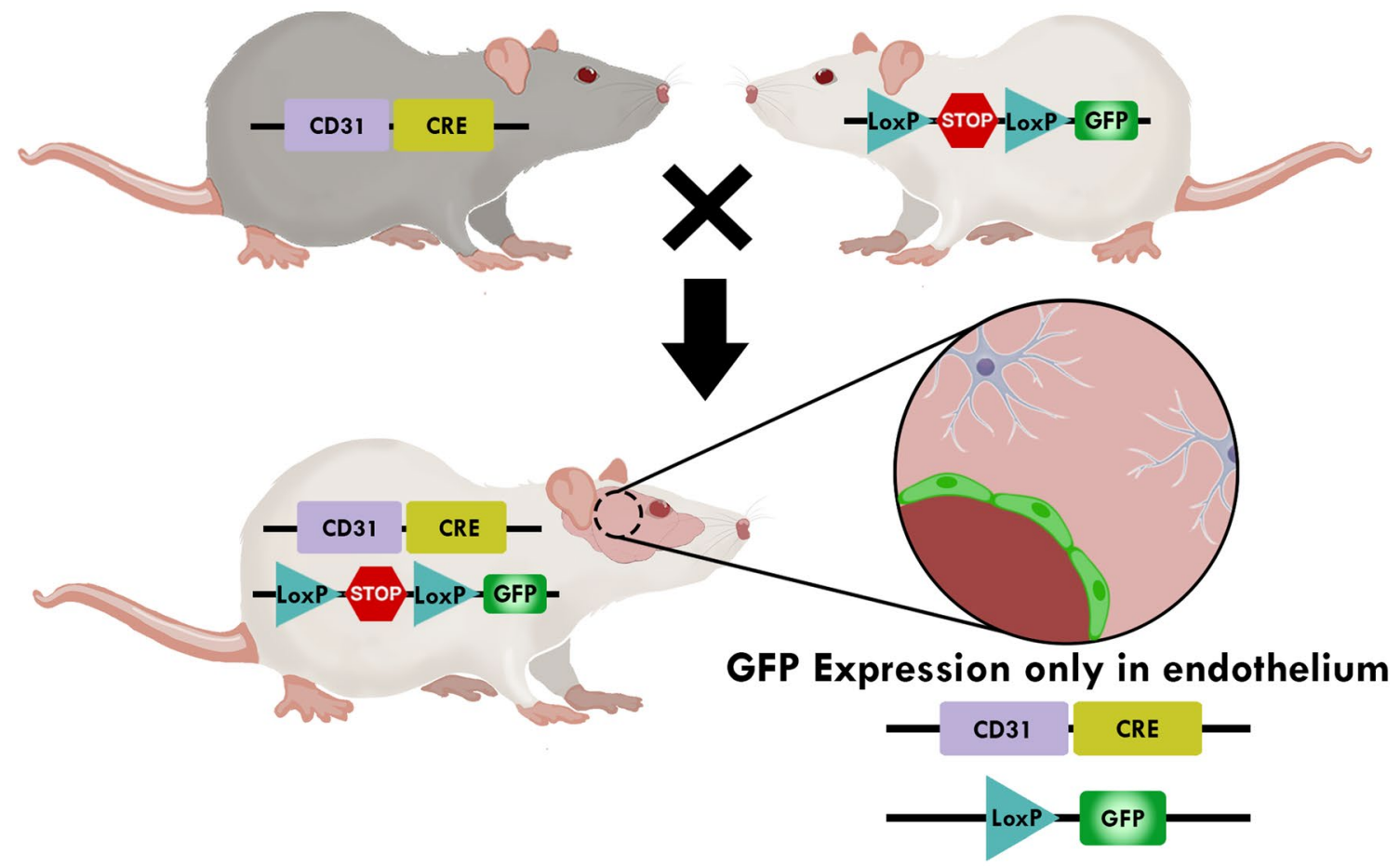

B Inducible Cre Line

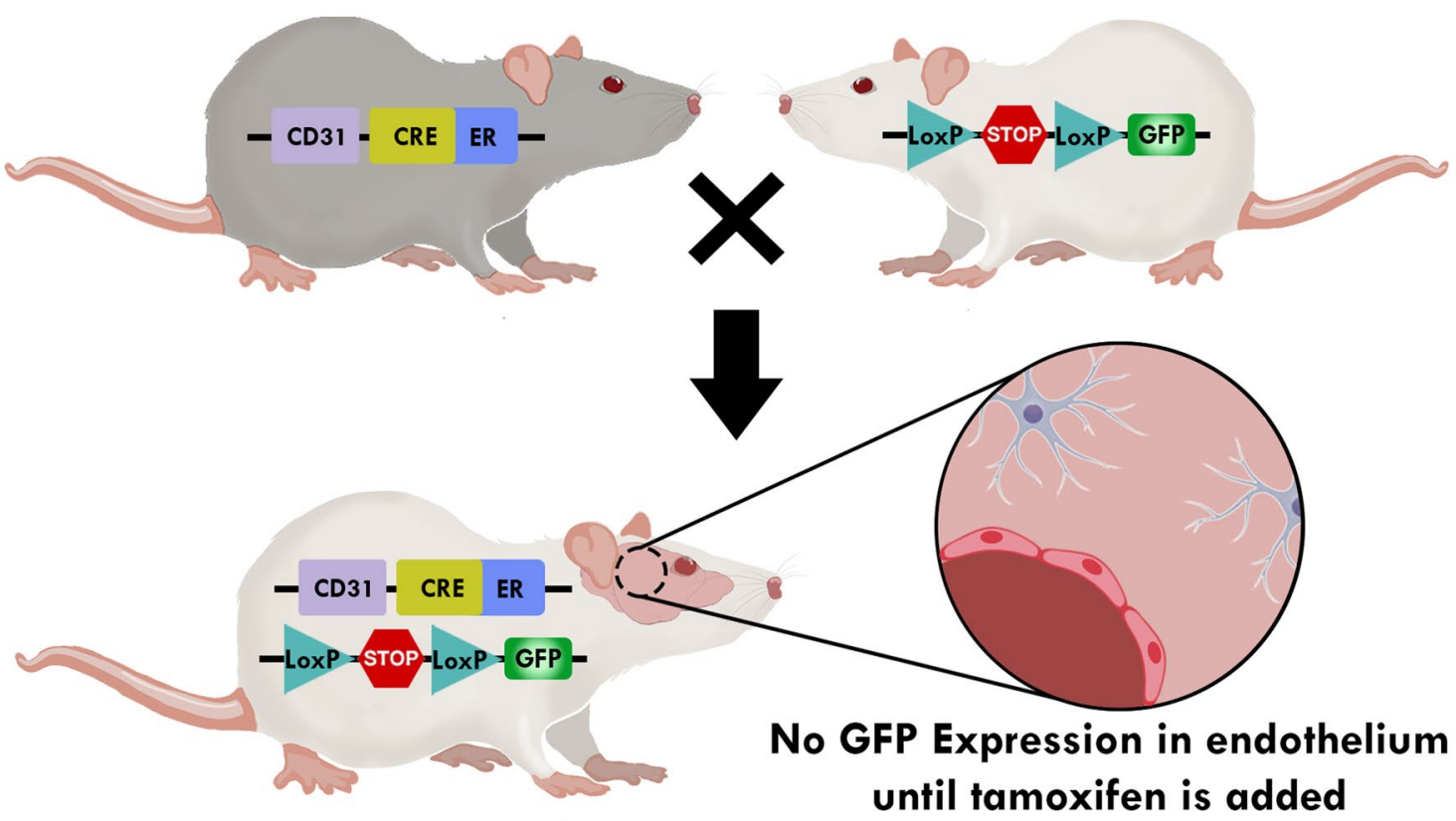

Fig. 2 Schematic of non-inducible and inducible Cre lines. A Noninducible Cre lines depend solely on the activity of their cell specific promoter. When both mouse lines are crossed Cre recombinase functions to excise the stop codon in front of green fluorescent protein (GFP) which turns GFP production on in cells where CD31 is active, in this example it is endothelial cells. B In an inducible Cre line, Cre is fused to mutated hormone-binding domains of the estrogen receptor. Cre-ER is inactive until tamoxifen is added. Inducible lines allow for both spatial and temporal control by combining the tissue-specific expression of Cre-ER by CD31 and its tamoxifen-dependent activity of the enzyme 
used marker for pericyte identification. PDGFR $\beta / P D G F \beta$ signaling is essential for pericyte maintenance and loss of that signaling leads to a progressive depletion of pericytes in vivo (Daneman et al. 2010; Nikolakopoulou et al. 2017). However, PDGFR $\beta$ is not fully specific for pericytes as it is also expressed in neural progenitor cells, glia, and fibroblast cells during injury (Kyyriainen et al. 2017). Chondroitin sulfate proteoglycan $4 /$ neural glial antigen 2 (NG2) and aminopeptidase N (CD13) are the two most common markers co-stained with PDGFR $\beta$ to confirm pericyte identification (Hartmann et al. 2015). NG2 is expressed on the cell surface of pericytes during angiogenesis (Ozerdem et al. 2001) but also in oligodendrocyte progenitors, Schwann cells, and perineurial cells (Levine et al. 2001; Stallcup 2002). CD13 is a membrane bound protein originally identified as a marker for cells of myeloid origin and can be used as a surface marker for brain pericytes (Armulik et al. 2010). Melanoma cell adhesion molecule (CD146) has been used as a marker for pericytes of the NVU due to its involvement in PDGFR $\beta$ activation and BBB integrity (Chen et al. 2017; Patenaude et al. 2015). CD146 is expressed by endothelial cells in BBB development but not in mature vessels, ganglion cells, and activated T lymphocytes (Chen et al. 2017; Nodomi et al. 2016; Shih 1999; Wang and Yan 2013). Pericytes are also positive for neuroectodermal stem cell marker (nestin). Nestin is a type VI intermediate filament that is generally used for the identification of neural stem cells. Expression of nestin is higher in other regions of the brain and also present in endothelial cells adjacent to pericytes (Klein et al. 2014). Recent studies show that a FluoroNissl dye (NeuroTrace 500/525) can accurately label capillary pericytes in the live mouse brain. Normally this dye is used to label neurons in fixed tissue but when applied to living cells there is robust overlapping expression with endogenous PDGFR- $\beta$ and NG2-positive cells on brain capillaries. NeuroTrace $500 / 525$ can be used to visualize pericytes in live imaging of the mouse brain (Damisah et al. 2017). $\alpha$-smooth muscle actin (SMA) has been omitted from the list because of ongoing debate on whether pericytes express SMA. SMA specificity for pericytes in vivo is unknown, with little evidence showing pericytes express SMA in vitro.

A growing availability and efficiency of RNASequencing has led to the development of new gene expression libraries. A review of five RNA-Seq libraries for brain mural cells identified 260 genes that are significantly enriched in mural cells and can therefore be used to specifically identify pericytes (He et al. 2018). The list was validated by evaluating immunofluorescence imaging of brains stained with for vitronectin (high expression) and interferon reduced transmembrane protein 1 (low expression). Analysis of these markers showed enriched expression in pericytes and expected low levels of expression in other CNS cells.

\section{Drivers for Pericyte Expression}

PDGFR $\beta$-Cre mouse models have been the most common way of driving protein expression in pericytes. PDGFR $\beta$-Cre models are available in constitutively active (Cuttler et al. 2011; Foo et al. 2006) and inducible forms (Cuttler et al. 2011; Gerl et al. 2015; Kruse et al. 2019). The inducible PDGFR $\beta-P 2 A-C r e E R^{\mathrm{T} 2}$ model has been validated with coimmunostaining and time course experiments to test pericyte expression and has high levels of Cre recombinase in pericytes of the retina and brain (Cuervo et al. 2017). While PDGFR $\beta$-Cre mouse models work well, PDGFR $\beta$ alone is far from being specific to pericytes (Sweeney et al. 2016). As a driver alone, PDGFR $\beta$ can lead to unwanted expression in other cell types that express this marker protein and were described above. Therefore, a two-driver promoter model can increase specificity of pericyte responses. A recent advancement in the field is the creation of a PDGFR $\beta / N G 2$ inducible mouse model (Kisler et al. 2020), which is consistent with the immunofluorescence approach of using at least two markers for pericyte identification. The pericyte-CreER model has flp recombinase under the control of PDGFR $\beta$ and a stop cassette under the control of the NG2 promoter (Nikolakopoulou et al. 2019). After tamoxifen injection only cells that have both an active NG2 and PDGFR $\beta$ will express the protein of interest.

\section{Astrocytes}

Astrocytes are specialized glial cells that originate from progenitor cells in the neuroepithelium of the developing nervous system (Rowitch and Kriegstein 2010; Tabata 2015). They form a glial network that ensheathe both neurons and blood vessels of the CNS (Vasile et al. 2017). Their connection between blood vessels and neurons allows for neurovascular coupling which includes the dilation/contraction of smooth muscle cells that surround vessels (Haydon and Carmignoto 2006). Research has shown that they have an active role in information processing and BBB control, making astrocytes an important cell to understand neurological diseases (Dossi et al. 2018; Guillamon-Vivancos et al. 2015). Astrocytes are not a homogenous population and therefore no single and fully specific marker exists to target all of them (Yoon et al. 2017). Glial fibrillary acidic protein (GFAP) (Table 1) is an intermediate filament expressed by reactive astrocytes, progenitor cells (Garcia et al. 2004; Zhang and Jiao 2015) and fibroblasts (Hainfellner et al. 2001; Sofroniew and 
Vinters 2010). Interestingly, GFAP-positive progenitor cells contribute to the development of vascular smooth muscle cells and endothelial cells (Osman et al. 2020). In the peripheral nervous system, GFAP-positive staining has been demonstrated in Schwann cells, enteric glial cells, and satellite cells of human sensory ganglia. As the most common marker for astrocyte cell body visualization, GFAP has been well categorized use in vivo and in vitro (Garcia et al. 2004; Zhuo et al. 2001). While it is uniformly expressed by astrocytes in cultures, in vivo GFAP has been shown to favor white matter astrocytes (Lundgaard et al. 2014) with only about $15 \%$ of the total astrocyte population showing positive staining (Bushong et al. 2002; Cahoy et al. 2008). One of the reasons for this selective staining may be due to GFAP upregulation in reactive astrocytes (Sofroniew and Vinters 2010). Astrocytes in the corpus callosum, cerebral peduncle, and especially the hippocampus preferentially express GFAP (Zhang et al. 2019).

Another marker for staining of astrocytes is aldehyde dehydrogenase 1 family member L1 (ALDH1L1) which is expressed in astrocytes but also in neural stem cells (Foo and Dougherty 2013). ALDH1L1 is highly specific and more widely expressed across the astrocyte population compared to GFAP (Cahoy et al. 2008). Even though ALDH1L1 is more inclusive than GFAP, the antibodies are reported to be difficult to work with, leaving GFAP as the most commonly used astrocyte marker. Glutamate transporters, such as excitatory amino acid transporter 1 (EAAT1 or glutamate aspartate transporter 1, GLAST1) and EAAT2 (GLAST 2), are present on astrocyte membranes and are in higher concentrations in astrocytes near capillaries or neuronal synapses (Parkin et al. 2018). Due to their location, EAAT1 and 2 can be used as regional markers of astrocytes. However, they can also be found in microglia, and oligodendrocytes, even though in lower concentrations (Kondo et al. 1995; Parkin et al. 2018). Aquaporin 4 (AQP4) is the predominant water channel expressed in astrocytes and can be used to visualize astrocytic end feet (Michalski et al. 2017). AQP4 is highly expressed in reactive astrocytes but also in microglia (Ikeshima-Kataoka 2016). Calcium binding protein B (S100ß) is a glial specific protein that can be used to visualize a subset of mature astrocytes that ensheathe blood vessels (Raponi et al. 2007). In contrast to GFAP, S100 $\beta$ is a more suitable marker to target all astrocytes but is particularly good to target astrocytes of the cortex and thalamus (Zhang et al. 2019). S100 $\beta$ is also expressed by oligodendrocytes, oligodendrocyte progenitor cells, and microglia (Cahoy et al. 2008; Raponi et al. 2007). Plasma levels of soluble $\mathrm{S} 100 \beta$ are also used as a marker of BBB disruption (Blyth et al. 2009; Koh and Lee 2014). Aldolase $\mathrm{C}$ (Aldoc) has been shown to localize in astrocytes of the cerebrum, Purkinje cells in the cerebellum, and large gray matter neurons. Aldoc is not usually used as an astrocyte biomarker due to lack of specificity (Fujita et al. 2014).

\section{Drivers for Astrocyte Expression}

GFAP and ALDH1L1 are the most specific genetic drivers for astrocytes. Depending on the brain region, GFAP Cre mouse model (hGFAP-CreERT2xAi14) has been characterized to have between 50 and $89 \%$ coverage of astrocytes, with specificity for astrocytes ranging between 52 and $92 \%$. Characterizations of different GFAP Cre-strains have shown significantly less coverage and specificity in the cortex, suggesting that specificity and coverage are also dependent on the strain and method of induction (Park et al. 2018). In contrast, Aldh1L1-Cre/ERT2 mice have very high levels of expression in astrocytes, and no detectable expression in neurons (Winchenbach et al. 2016). Both Cre lines can be crossed to any desired proteins of interest, which are usually available through commercial methods, making Cre mouse models a useful genetic tool.

\section{Microglia}

Microglia are glial cells located throughout the brain and spinal cord and they serve as the main form of immune defense for the CNS (Li and Barres 2018). During insult to the CNS, microglia transform from a resting to an activated state and their gene expression changes to perform their immune role (Cronk and Kipnis 2013). The heterogeneity and plasticity of microglia make them a difficult cell to target and must be considered in the selection of effective markers. A set of common markers used for microglia are integrin alpha M subunit (CD11b) (Gong et al. 2019), Ionized calcium binding adaptor molecule 1 (Iba1) (Burkovetskaya et al. 2020), CX3C chemokine receptor 1 (CX3CR1) (Chen et al. 2002), and CD45 (Majerova et al. 2019). All these markers can be used to distinguish microglia from other cells of the CNS but not from peripheral immune cells in the meningeal spaces or perivascular macrophages in the perivascular spaces. A few promising discoveries made in the field indicated that Transforming growth factor $\beta$ (TGF $\beta$ )-dependent signaling might be useful in distinguishing microglia from macrophages (Butovsky et al. 2014). Proteins related to the TGF $\beta$ pathway, such as transmembrane protein 119 (Tmem119) (Satoh et al. 2016), purinergic receptor (P2RY12) (Amadio et al. 2014; Haynes et al. 2006), Fc Receptor like S (FCRLS) (Butovsky and Weiner 2018), and hexosaminidase subunit beta (HexB) (Butovsky et al. 2014), function as stably expressed microglial-specific markers. The function of Tmem119 is not fully understood; 
however, its expression patterns show strong levels of expression in microglia (Butovsky et al. 2014; Butovsky and Weiner 2018). Tmem119 has been studied under a variety of disease conditions (e.g., sciatic nerve injury-induced microglial activation, lipopolysaccharide-induced systemic inflammation, optic nerve crush injury, Alzheimer's disease, or multiple sclerosis) and was shown to maintain stable but low expression in activated microglia (Bennett et al. 2016).

P2RY12 is found on the surface of blood platelets, where it is an important clotting regulator (Dorsam and Kunapuli 2004). However, its expression in the CNS appears to be specific to microglia and is necessary for microglial functions, including neuronal monitoring and neuroprotection (Cserep et al. 2020). In contrast to Tmem119, P2RY12 expression is enhanced by anti-inflammatory cytokines, which may make it a better marker for microglia. Overall, P2RY12 is regarded as one of the most specific available markers for yolk-sac derived microglia (Jurga et al. 2020).

Among other potential microglial markers, FCRLS is highly active in rodent microglia; however, there is no known expression of this gene in human microglia. Gene expression shows high and stable levels of FCRLS expression in isolated microglia and no expression in macrophages (Butovsky et al. 2014). Hexb is an enzyme responsible for the degradation of ganglioside and molecules containing terminal $\mathrm{N}$-acetyl hexosamine (Kyrkanides et al. 2012). Hexb is required for microglial maintenance and while it has not been fully studied in a variety of pathological conditions, it maintains stable expression in several neurodegenerative and neuroinflammatory conditions (Butovsky et al. 2014).

In studies of neuroinflammation it is not only important to distinguish microglia and macrophages but also resting and active microglia. Microglia are the resident immune cell, and therefore are equipped with tools to recognize and repair pathological conditions. Proteins associated with MHC complexes, Inflammatory signal production and release, Toll-like receptors (TLRs), and phagocytosis can be used as markers for microglial activation (Boche et al. 2013). Examples of such proteins are CD16 (Kigerl et al. 2009), CD32 (Kigerl et al. 2009), Major histocompatibility complex II (MHC II) (Smith and Dragunow 2014), and CD163 (Etzerodt et al. 2014); however, there are many markers that can be used for microglial activation (Jurga et al. 2020). These markers are upregulated during pathological conditions and when used together with generic microglial markers could altogether distinguish resting and active microglia.

\section{Drivers for Microglial Expression}

CX3CR1-Cre reporter mice have been the most common animal model for microglial expression (Jung et al.
2000; Wieghofer and Prinz 2016). These mice are available in both inducible and constitutively active forms (Fig. 2). Reporter expression can be found in monocytes, dendritic cells, NK cells, as well as T and B lymphocytes (Goldmann et al. 2016). However, there have been valid concerns over the leakiness (to varying degrees and depending on the specific line) of CX3CR1-Cre GFP reporter lines in neurons. Furthermore, CX3CR1 cannot be used to distinguish the effects of microglia vs. infiltrating macrophages, which is critical to understanding the role of microglia in health and disease (Jurga et al. 2020). Instead, Tmem119-EGFP (Kaiser and Feng 2019), Tmem119-CreERT2 (Kaiser and Feng 2019), P2RY12CreER (McKinsey et al. 2020), and Hexb-CreERT2 (Masuda et al. 2020) are promising and microglia-specific models that have been developed and published in the last 2 years. Tmem119-EGFP and Tmem119-CreERT2 were generated using donor DNA from peptide porcine teschovirus-1 polyprotein and EGFP (P2AEGFP) or CreERT2 (P2A-CreERT2) along with CRISPR Cas9 into C57BL/B6N zygotes. Strains were validated by PCR products and confirmed specific insertion of the construct into the Tmem119 locus. Using confocal microscopy for both the inducible and non-inducible lines, GFP expression was confirmed in microglia but not perivascular, meningeal or choroid plexus macrophages. Unfortunately, the lines were not studied under pathological conditions in which Tmem119-related expression is expected to decrease.

P2RY12-CreER is an inducible Cre line based on Cre and the estrogen receptor fusion protein. P2RY12 is considered to be one of the most specific microglial markers. While its expression was observed in a subset of macrophages in the dura matter, it was absent in macrophages or circulating monocytes. Outside of the CNS, P2RY12 expression was observed in subsets of CD206+ Cx3cr1+ cells in the heart, intestine, lung, and spleen as well as in LYVE1+ cells. P2RY12-CreER models were tested in disease models of acute ischemic stroke and multiple sclerosis, and it was demonstrated that P2RY12 expression was maintained in areas of injury.

Hexb-tdT a reporter line and Hexb-CreERT2 a line for Cre inducible expression is based on HexB, which is a stable core microglial protein. Hexb-CreERT2 was studied in the 5xFAD mouse model of Alzheimer's disease and no Hexb expression associated with macrophages was observed in the CNS. The reported advantages of Hexb is that there is little to no downregulation during inflammatory conditions in comparison to P2RY12 and Tmem119. Moreover, Hexb expression is enhanced in parenchymal microglia than other models for microglial targeting. 


\section{Conclusions and Advancements/ Perspectives of the Field}

Formed by neurons, endothelial cells, pericytes, astrocytes, microglia, and the extracellular matrix, the NVU controls and regulates BBB integrity and cerebral blood flow. To maintain the BBB, various cell types of the NVU communicate and develop individual tasks (Kisler et al. 2017; Muoio et al. 2014). Dysfunction of the BBB is associated with multiple neurological disorders for which an optimal identification of the NVU subtypes is essential for understanding the underlying pathology. Currently, the markers and drivers available to identify cells of the NVU can lead to a cross reactivity, limiting the interpretation of the findings. Several new approaches are successfully being developed to solve this residual challenge.

Cre models are a key method for spatial and temporal control of gene expression and protein targeting. Some pitfalls in Cre systems is that there is a permanent modification to the genome induced by $\mathrm{Cre}$ and their dependency on available tissue-specific markers to drive protein expression. To solve these problems, this system is in constant improvement. One example of the extraordinary level of sophistication that is being achieved is the use of more than one driver for an increase in cell specificity. As an example, pericyteCreER mentioned above crosses NG2 and PDGFR $\beta$, which increases specificity for pericytes. Double promoter models allow for more advanced animal models targeting the NVU. Another recent advancement in the field is the possibility of generating a model that includes both, a specific target, and reversible transgenic misexpression with spaciotemporal resolution. With this model, gene expression depends on the intersection of previous Cre exposure and (r) tTA activity (Rosello-Diez et al. 2018). An example of the possibilities that this technology provides is the development of the intersectional Dragon-DTA model (Ahmadzadeh et al. 2020), which allows for acute tissue-specific cell ablation with spatiotemporal exactitude. With a growing number of commercially available Cre models and techniques, there are many possibilities to generate more advanced mouse lines to target the NVU.

Additionally, we can learn a lot from how other fields solve the problem of in vivo targeting. In the cancer field the use of lentiviruses to recognize cancerous tissue is becoming an important development. Lentiviruses can recognize and deliver a plasmid to tumor cells (Russell and Peng 2007). The viruses are manipulated to take advantage of cancer morphology and aberrant signaling so that viral replication is only viable in a cancer cell (Bell et al. 2003). While the brain represents a challenging target for gene delivery, certain viruses have already proved capable of preferential delivery to CNS cells. Adeno-associated virus serotype 2 (AAV2) infects neurons preferentially, while AAV5 efficiently transduces Purkinje cells, but not granule cells (Bartlett et al. 1998; Haberman et al. 2002). Among AAVs, AAV9 has the highest penetration through the BBB (Saraiva et al. 2016). Targeting the neurovascular unit could be a matter of finding the right serotype for the cell or manipulating viral vectors to create an environment for specific gene delivery.

Finally, the growing understanding and availability of nanoparticles offers another way of studying the NVU. Their small size and use of biodegradable materials make nanoparticles a unique system for targeted delivery into cells or tissues (Thurn et al. 2007). For example, glucose-coated gold nanoparticles can cross endothelium via passive uptake and concentrate in astrocytes in vivo (Gromnicova et al. 2013). Nanotechnology also allows for drugs to effectively cross the BBB via transient pathways without altering vascular and neurological integrity (Ding et al. 2014; Osborne et al. 2020; Yamaguchi et al. 2020; Zhou et al. 2018). A growing ability to manipulate the properties of nanoparticles can prove to be a great advantage in targeting NVU cells.

Here we summarize the current knowledge concerning the markers and drivers of the NVU. To better understand the NVU and its role in brain pathology, we must explore and be able to specifically identify and manipulate different NVU cell types. New technologies to approach the problem are being developed and will help us better understand the molecular basis of the BBB and neurovascular interactions in health and neurological disorders.

Acknowledgements Supported by the National Institutes of Health (NIH), Grants MH122235, MH072567, HL126559, DA044579, DA039576, DA040537, DA050528, and DA047157 and by the NSC Grant 2019/35/B/NZ7/03155. Dr. Torices was supported by an American Heart Association (AHA) postdoctoral fellowship (20POST35211181)

\section{Declarations}

Conflict of interest The authors declare that they have no conflict of interest.

Open Access This article is licensed under a Creative Commons Attribution 4.0 International License, which permits use, sharing, adaptation, distribution and reproduction in any medium or format, as long as you give appropriate credit to the original author(s) and the source, provide a link to the Creative Commons licence, and indicate if changes were made. The images or other third party material in this article are included in the article's Creative Commons licence, unless indicated otherwise in a credit line to the material. If material is not included in the article's Creative Commons licence and your intended use is not permitted by statutory regulation or exceeds the permitted use, you will need to obtain permission directly from the copyright holder. To view a copy of this licence, visit http://creativecommons. org/licenses/by/4.0/. 


\section{References}

Abbott NJ, Ronnback L, Hansson E (2006) Astrocyte-endothelial interactions at the blood-brain barrier. Nat Rev Neurosci 7:41-53. https://doi.org/10.1038/nrn1824

Adams RA, Schachtrup C, Davalos D, Tsigelny I, Akassoglou K (2007) Fibrinogen signal transduction as a mediator and therapeutic target in inflammation: lessons from multiple sclerosis. Curr Med Chem 14:2925-2936. https://doi.org/10.2174/092986707782360 015

Ahmadzadeh E et al (2020) A collection of genetic mouse lines and related tools for inducible and reversible intersectional misexpression. Development. https://doi.org/10.1242/dev.186650

Ajami B, Bennett JL, Krieger C, McNagny KM, Rossi FM (2011) Infiltrating monocytes trigger EAE progression, but do not contribute to the resident microglia pool. Nat Neurosci 14:1142-1149. https://doi.org/10.1038/nn.2887

Amadio S, Parisi C, Montilli C, Carrubba AS, Apolloni S, Volonte C (2014) P2Y(12) receptor on the verge of a neuroinflammatory breakdown. Mediators Inflamm 2014:975849. https://doi.org/10. 1155/2014/975849

Amarenco P, Bogousslavsky J, Caplan LR, Donnan GA, Hennerici MG (2009) Classification of stroke subtypes. Cerebrovasc Dis 27:493-501. https://doi.org/10.1159/000210432

Arch AE, Weisman DC, Coca S, Nystrom KV, Wira CR 3rd, Schindler JL (2016) Missed ischemic stroke diagnosis in the Emergency Department by Emergency Medicine and Neurology Services. Stroke 47:668-673. https://doi.org/10.1161/STROKEAHA.115. 010613

Armulik A et al (2010) Pericytes regulate the blood-brain barrier. Nature 468:557-561. https://doi.org/10.1038/nature09522

Armulik A, Genove G, Betsholtz C (2011) Pericytes: developmental, physiological, and pathological perspectives, problems, and promises. Dev Cell 21:193-215. https://doi.org/10.1016/j.devcel. 2011.07.001

Attwell D, Mishra A, Hall CN, O'Farrell FM, Dalkara T (2016) What is a pericyte? J Cereb Blood Flow Metab 36:451-455. https:// doi.org/10.1177/0271678X15610340

Bartlett JS, Samulski RJ, McCown TJ (1998) Selective and rapid uptake of adeno-associated virus type 2 in brain. Hum Gene Ther 9:1181-1186. https://doi.org/10.1089/hum.1998.9.8-1181

Bautch VL, Caron KM (2015) Blood and lymphatic vessel formation. Cold Spring Harb Perspect Biol 7:a008268. https://doi.org/10. 1101/cshperspect.a008268

Bell JC, Lichty B, Stojdl D (2003) Getting oncolytic virus therapies off the ground. Cancer Cell 4:7-11. https://doi.org/10.1016/s15356108(03)00170-3

Bennett ML et al (2016) New tools for studying microglia in the mouse and human CNS. Proc Natl Acad Sci USA 113:E1738-E1746. https://doi.org/10.1073/pnas.1525528113

Bernacki J, Dobrowolska A, Nierwinska K, Malecki A (2008) Physiology and pharmacological role of the blood-brain barrier. Pharmacol Rep 60:600-622

Bertrand L, Cho HJ, Toborek M (2019a) Blood-brain barrier pericytes as a target for HIV-1 infection. Brain 142:502-511. https://doi. org/10.1093/brain/awy339

Bertrand L, Meroth F, Tournebize M, Leda AR, Sun E, Toborek M (2019b) Targeting the HIV-infected brain to improve ischemic stroke outcome. Nat Commun. https://doi.org/10.1038/ s41467-019-10046-x

Blyth BJ et al (2009) Validation of serum markers for blood-brain barrier disruption in traumatic brain injury. J Neurotrauma 26:14971507. https://doi.org/10.1089/neu.2008.0738

Boche D, Perry VH, Nicoll JA (2013) Review: activation patterns of microglia and their identification in the human brain.
Neuropathol Appl Neurobiol 39:3-18. https://doi.org/10.1111/ nan. 12011

Burkovetskaya ME, Small R, Guo L, Buch S, Guo ML (2020) Cocaine self-administration differentially activates microglia in the mouse brain. Neurosci Lett 728:134951. https://doi.org/10.1016/j.neulet.2020.134951

Bushong EA, Martone ME, Jones YZ, Ellisman MH (2002) Protoplasmic astrocytes in CA1 stratum radiatum occupy separate anatomical domains. J Neurosci 22:183-192

Butovsky O, Weiner HL (2018) Microglial signatures and their role in health and disease. Nat Rev Neurosci 19:622-635. https://doi. org/10.1038/s41583-018-0057-5

Butovsky O et al (2014) Identification of a unique TGF-beta-dependent molecular and functional signature in microglia. Nat Neurosci 17:131-143. https://doi.org/10.1038/nn.3599

Cahoy JD et al (2008) A transcriptome database for astrocytes, neurons, and oligodendrocytes: a new resource for understanding brain development and function. J Neurosci 28:264-278. https://doi. org/10.1523/JNEUROSCI.4178-07.2008

Castro V et al (2016) Occludin controls HIV transcription in brain pericytes via regulation of SIRT-1 activation. FASEB J 30:12341246. https://doi.org/10.1096/fj.15-277673

Chatterjee S, Naik UP (2012) Pericyte-endothelial cell interaction: a survival mechanism for the tumor vasculature. Cell Adhes Migr 6:157-159. https://doi.org/10.4161/cam.20252

Chen S, Luo D, Streit WJ, Harrison JK (2002) TGF-beta1 upregulates CX3CR1 expression and inhibits fractalkine-stimulated signaling in rat microglia. J Neuroimmunol 133:46-55. https://doi.org/10. 1016/s0165-5728(02)00354-5

Chen J et al (2017) CD146 coordinates brain endothelial cell-pericyte communication for blood-brain barrier development. Proc Natl Acad Sci USA 114:E7622-E7631. https://doi.org/10.1073/pnas. 1710848114

Cho HJ, Kuo AM, Bertrand L, Toborek M (2017) HIV alters gap junction-mediated intercellular communication in human brain pericytes. Front Mol Neurosci 10:410. https://doi.org/10.3389/ fnmol.2017.00410

Correale J, Gaitan MI, Ysrraelit MC, Fiol MP (2017) Progressive multiple sclerosis: from pathogenic mechanisms to treatment. Brain 140:527-546. https://doi.org/10.1093/brain/aww258

Cronk JC, Kipnis J (2013) Microglia-the brain's busy bees. F1000Prime Rep 5:53. https://doi.org/10.12703/P5-53

Cserep C et al (2020) Microglia monitor and protect neuronal function through specialized somatic purinergic junctions. Science 367:528-537. https://doi.org/10.1126/science.aax6752

Cuervo H, Pereira B, Nadeem T, Lin M, Lee F, Kitajewski J, Lin CS (2017) PDGFRbeta-P2A-CreER(T2) mice: a genetic tool to target pericytes in angiogenesis. Angiogenesis 20:655-662. https:// doi.org/10.1007/s10456-017-9570-9

Cuttler AS, LeClair RJ, Stohn JP, Wang Q, Sorenson CM, Liaw L, Lindner V (2011) Characterization of Pdgfrb-Cre transgenic mice reveals reduction of ROSA26 reporter activity in remodeling arteries. Genesis 49:673-680. https://doi.org/10.1002/dvg.20769

Damisah EC, Hill RA, Tong L, Murray KN, Grutzendler J (2017) A fluoro-Nissl dye identifies pericytes as distinct vascular mural cells during in vivo brain imaging. Nat Neurosci 20:1023-1032. https://doi.org/10.1038/nn.4564

Daneman R, Prat A (2015) The blood-brain barrier. Cold Spring Harb Perspect Biol 7:a020412. https://doi.org/10.1101/cshperspect. a020412

Daneman R, Zhou L, Kebede AA, Barres BA (2010) Pericytes are required for blood-brain barrier integrity during embryogenesis. Nature 468:562-566. https://doi.org/10.1038/nature09513

De Palma M, Venneri MA, Galli R, Sergi Sergi L, Politi LS, Sampaolesi M, Naldini L (2005) Tie2 identifies a hematopoietic 
lineage of proangiogenic monocytes required for tumor vessel formation and a mesenchymal population of pericyte progenitors. Cancer Cell 8:211-226. https://doi.org/10.1016/j.ccr.2005. 08.002

Dejana E, Tournier-Lasserve E, Weinstein BM (2009) The control of vascular integrity by endothelial cell junctions: molecular basis and pathological implications. Dev Cell 16:209-221. https://doi. org/10.1016/j.devcel.2009.01.004

Ding $\mathrm{H}$ et al (2014) Enhanced blood-brain barrier transmigration using a novel transferrin embedded fluorescent magneto-liposome nanoformulation. Nanotechnology 25:055101. https://doi.org/ 10.1088/0957-4484/25/5/055101

Dorsam RT, Kunapuli SP (2004) Central role of the P2Y12 receptor in platelet activation. J Clin Investig 113:340-345. https://doi. org/10.1172/JCI20986

Dossi E, Vasile F, Rouach N (2018) Human astrocytes in the diseased brain. Brain Res Bull 136:139-156. https://doi.org/10.1016/j. brainresbull.2017.02.001

Dustin ML, Rothlein R, Bhan AK, Dinarello CA, Springer TA (2011) Induction by IL 1 and interferon-gamma: tissue distribution, biochemistry, and function of a natural adherence molecule (ICAM1). J. Immunol. 1986. 137: 245-254. J Immunol 186:5024-5033

Etzerodt A et al (2014) Structural basis for inflammation-driven shedding of CD163 ectodomain and tumor necrosis factor-alpha in macrophages. J Biol Chem 289:778-788. https://doi.org/10.1074/ jbc.M113.520213

Foo LC, Dougherty JD (2013) Aldh1L1 is expressed by postnatal neural stem cells in vivo. Glia 61:1533-1541. https://doi.org/ 10.1002/glia.22539

Foo SS et al (2006) Ephrin-B2 controls cell motility and adhesion during blood-vessel-wall assembly. Cell 124:161-173. https://doi. org/10.1016/j.cell.2005.10.034

Fuhrmann M et al (2010) Microglial Cx3cr1 knockout prevents neuron loss in a mouse model of Alzheimer's disease. Nat Neurosci 13:411-413. https://doi.org/10.1038/nn.2511

Fujita $\mathrm{H}$ et al (2014) Detailed expression pattern of aldolase C (Aldoc) in the cerebellum, retina and other areas of the CNS studied in Aldoc-Venus knock-in mice. PLoS One 9:e86679. https://doi.org/ 10.1371/journal.pone.0086679

Fukuhara S, Sako K, Noda K, Nagao K, Miura K, Mochizuki N (2009) Tie2 is tied at the cell-cell contacts and to extracellular matrix by angiopoietin-1. Exp Mol Med 41:133-139. https://doi.org/10. 3858/emm.2009.41.3.016

Garcia AD, Doan NB, Imura T, Bush TG, Sofroniew MV (2004) GFAP-expressing progenitors are the principal source of constitutive neurogenesis in adult mouse forebrain. Nat Neurosci 7:1233-1241. https://doi.org/10.1038/nn1340

Gerl K, Miquerol L, Todorov VT, Hugo CPM, Adams RH, Kurtz A, Kurt B (2015) Inducible glomerular erythropoietin production in the adult kidney. Kidney Int 88:1345-1355. https://doi.org/ 10.1038/ki.2015.274

Goldmann T et al (2016) Origin, fate and dynamics of macrophages at central nervous system interfaces. Nat Immunol 17:797-805. https://doi.org/10.1038/ni.3423

Gong W et al (2019) Involvement of the microglial NLRP3 inflammasome in the anti-inflammatory effect of the antidepressant clomipramine. J Affect Disord 254:15-25. https://doi.org/10. 1016/j.jad.2019.05.009

Gromnicova R et al (2013) Glucose-coated gold nanoparticles transfer across human brain endothelium and enter astrocytes in vitro. PLoS One 8:e81043. https://doi.org/10.1371/journal.pone.00810 43

Guillamon-Vivancos T, Gomez-Pinedo U, Matias-Guiu J (2015) Astrocytes in neurodegenerative diseases (I): function and molecular description. Neurologia 30:119-129. https://doi.org/10.1016/j. nrl.2012.12.007
Haarmann A et al (2015) Soluble VCAM-1 impairs human brain endothelial barrier integrity via integrin alpha-4-transduced outside-in signalling. Acta Neuropathol 129:639-652. https:// doi.org/10.1007/s00401-015-1417-0

Haberman R, Criswell H, Snowdy S, Ming Z, Breese G, Samulski R, McCown T (2002) Therapeutic liabilities of in vivo viral vector tropism: adeno-associated virus vectors, NMDAR1 antisense, and focal seizure sensitivity. Mol Ther 6:495-500. https://doi. org/10.1006/mthe.2002.0701

Hainfellner JA, Voigtlander T, Strobel T, Mazal PR, Maddalena AS, Aguzzi A, Budka H (2001) Fibroblasts can express glial fibrillary acidic protein (GFAP) in vivo. J Neuropathol Exp Neurol 60:449-461. https://doi.org/10.1093/jnen/60.5.449

Hartmann DA, Underly RG, Watson AN, Shih AY (2015) A murine toolbox for imaging the neurovascular unit. Microcirculation 22:168-182. https://doi.org/10.1111/micc. 12176

Haydon PG, Carmignoto G (2006) Astrocyte control of synaptic transmission and neurovascular coupling. Physiol Rev 86:1009-1031. https://doi.org/10.1152/physrev.00049.2005

Haynes SE, Hollopeter G, Yang G, Kurpius D, Dailey ME, Gan WB, Julius D (2006) The P2Y12 receptor regulates microglial activation by extracellular nucleotides. Nat Neurosci 9:1512-1519. https://doi.org/10.1038/nn1805

He L et al (2018) Single-cell RNA sequencing of mouse brain and lung vascular and vessel-associated cell types. Sci Data 5:180160. https://doi.org/10.1038/sdata.2018.160

Heppner FL et al (2005) Experimental autoimmune encephalomyelitis repressed by microglial paralysis. Nat Med 11:146-152. https:// doi.org/10.1038/nm1177

Hill SA et al (2019) Sonic hedgehog signaling in astrocytes mediates cell type-specific synaptic organization. Elife. https://doi.org/10. 7554/eLife. 45545

Ikeshima-Kataoka H (2016) Neuroimmunological implications of AQP4 in astrocytes. Int J Mol Sci. https://doi.org/10.3390/ijms1 7081306

Jahan R et al (2019) Association between time to treatment with endovascular reperfusion therapy and outcomes in patients with acute ischemic stroke treated in clinical practice. JAMA 322:252-263. https://doi.org/10.1001/jama.2019.8286

Jickling GC, Sharp FR (2015) Biomarker panels in ischemic stroke. Stroke 46:915-920. https://doi.org/10.1161/STROKEAHA.114. 005604

Jung S, Aliberti J, Graemmel P, Sunshine MJ, Kreutzberg GW, Sher A, Littman DR (2000) Analysis of fractalkine receptor CX(3) CR1 function by targeted deletion and green fluorescent protein reporter gene insertion. Mol Cell Biol 20:4106-4114. https://doi. org/10.1128/mcb.20.11.4106-4114.2000

Jurga AM, Paleczna M, Kuter KZ (2020) Overview of general and discriminating markers of differential microglia phenotypes. Front Cell Neurosci 14:198. https://doi.org/10.3389/fncel.2020.00198

Kaiser T, Feng G (2019) Tmem119-EGFP and Tmem119-CreERT2 transgenic mice for labeling and manipulating microglia. eNeuro. https://doi.org/10.1523/ENEURO.0448-18.2019

Kigerl KA, Gensel JC, Ankeny DP, Alexander JK, Donnelly DJ, Popovich PG (2009) Identification of two distinct macrophage subsets with divergent effects causing either neurotoxicity or regeneration in the injured mouse spinal cord. J Neurosci 29:1343513444. https://doi.org/10.1523/JNEUROSCI.3257-09.2009

Kisanuki YY, Hammer RE, Miyazaki J, Williams SC, Richardson JA, Yanagisawa M (2001) Tie2-Cre transgenic mice: a new model for endothelial cell-lineage analysis in vivo. Dev Biol 230:230-242. https://doi.org/10.1006/dbio.2000.0106

Kisler K, Nelson AR, Montagne A, Zlokovic BV (2017) Cerebral blood flow regulation and neurovascular dysfunction in Alzheimer disease. Nat Rev Neurosci 18:419-434. https://doi.org/10.1038/nrn. 2017.48 
Kisler K, Nikolakopoulou AM, Sweeney MD, Lazic D, Zhao Z, Zlokovic $B V(2020)$ Acute ablation of cortical pericytes leads to rapid neurovascular uncoupling. Front Cell Neurosci 14:27. https://doi. org/10.3389/fncel.2020.00027

Klein D, Meissner N, Kleff V, Jastrow H, Yamaguchi M, Ergun S, Jendrossek V (2014) Nestin(+) tissue-resident multipotent stem cells contribute to tumor progression by differentiating into pericytes and smooth muscle cells resulting in blood vessel remodeling. Front Oncol 4:169. https://doi.org/10.3389/fonc.2014.00169

Koh SX, Lee JK (2014) S100B as a marker for brain damage and blood-brain barrier disruption following exercise. Sports Med 44:369-385. https://doi.org/10.1007/s40279-013-0119-9

Kondo K, Hashimoto H, Kitanaka J, Sawada M, Suzumura A, Marunouchi T, Baba A (1995) Expression of glutamate transporters in cultured glial cells. Neurosci Lett 188:140-142. https:// doi.org/10.1016/0304-3940(95)11408-o

Kong DH, Kim YK, Kim MR, Jang JH, Lee S (2018) Emerging roles of vascular cell adhesion molecule-1 (VCAM-1) in immunological disorders and cancer. Int J Mol Sci. https://doi.org/10.3390/ ijms 19041057

Kruse K et al (2019) N-cadherin signaling via Trio assembles adherens junctions to restrict endothelial permeability. J Cell Biol 218:299-316. https://doi.org/10.1083/jcb.201802076

Kyrkanides S, Brouxhon SM, Tallents RH, Miller JN, Olschowka JA, O'Banion MK (2012) Conditional expression of human betahexosaminidase in the neurons of Sandhoff disease rescues mice from neurodegeneration but not neuroinflammation. J Neuroinflamm 9:186. https://doi.org/10.1186/1742-2094-9-186

Kyyriainen J, Ekolle Ndode-Ekane X, Pitkanen A (2017) Dynamics of PDGFRbeta expression in different cell types after brain injury. Glia 65:322-341. https://doi.org/10.1002/glia.23094

Lai L, Bohnsack BL, Niederreither K, Hirschi KK (2003) Retinoic acid regulates endothelial cell proliferation during vasculogenesis. Development 130:6465-6474. https://doi.org/10.1242/dev.00887

Lassmann H (2010) Axonal and neuronal pathology in multiple sclerosis: what have we learnt from animal models. Exp Neurol 225:2-8. https://doi.org/10.1016/j.expneurol.2009.10.009

Lee YW, Hennig B, Fiala M, Kim KS, Toborek M (2001) Cocaine activates redox-regulated transcription factors and induces TNFalpha expression in human brain endothelial cells. Brain Res 920:125-133. https://doi.org/10.1016/s0006-8993(01)03047-5

Lengfeld JE et al (2017) Endothelial Wnt/beta-catenin signaling reduces immune cell infiltration in multiple sclerosis. Proc Natl Acad Sci USA 114:E1168-E1177. https://doi.org/10.1073/pnas. 1609905114

Levine JM, Reynolds R, Fawcett JW (2001) The oligodendrocyte precursor cell in health and disease. Trends Neurosci 24:39-47. https://doi.org/10.1016/s0166-2236(00)01691-x

Li Q, Barres BA (2018) Microglia and macrophages in brain homeostasis and disease. Nat Rev Immunol 18:225-242. https://doi.org/ 10.1038/nri.2017.125

Liu Z, Condello C, Schain A, Harb R, Grutzendler J (2010) CX3CR1 in microglia regulates brain amyloid deposition through selective protofibrillar amyloid-beta phagocytosis. J Neurosci 30:1709117101. https://doi.org/10.1523/JNEUROSCI.4403-10.2010

Lundgaard I, Osorio MJ, Kress BT, Sanggaard S, Nedergaard M (2014) White matter astrocytes in health and disease. Neuroscience 276:161-173. https://doi.org/10.1016/j.neuroscience.2013.10. 050

Majerova P et al (2019) Trafficking of immune cells across the bloodbrain barrier is modulated by neurofibrillary pathology in tauopathies. PLoS One 14:e0217216. https://doi.org/10.1371/journal. pone. 0217216

Masuda T et al (2020) Novel Hexb-based tools for studying microglia in the CNS. Nat Immunol 21:802-815. https://doi.org/10.1038/ s41590-020-0707-4
Mathiisen TM, Lehre KP, Danbolt NC, Ottersen OP (2010) The perivascular astroglial sheath provides a complete covering of the brain microvessels: an electron microscopic 3D reconstruction. Glia 58:1094-1103. https://doi.org/10.1002/glia.20990

Mazzetti S, Frigerio S, Gelati M, Salmaggi A, Vitellaro-Zuccarello L (2004) Lycopersicon esculentum lectin: an effective and versatile endothelial marker of normal and tumoral blood vessels in the central nervous system. Eur J Histochem 48:423-428. https:// doi.org/10.4081/916

McKinsey GL et al (2020) A new genetic strategy for targeting microglia in development and disease. Elife. https://doi.org/10.7554/ eLife. 54590

Merlini M, Meyer EP, Ulmann-Schuler A, Nitsch RM (2011) Vascular beta-amyloid and early astrocyte alterations impair cerebrovascular function and cerebral metabolism in transgenic arcAbeta mice. Acta Neuropathol 122:293-311. https://doi.org/10.1007/ s00401-011-0834-y

Michalski D et al (2017) Delayed histochemical alterations within the neurovascular unit due to transient focal cerebral ischemia and experimental treatment with neurotrophic factors. PLoS One 12:e174996. https://doi.org/10.1371/journal.pone.0174996

Minagar A, Alexander JS (2003) Blood-brain barrier disruption in multiple sclerosis. Mult Scler 9:540-549. https://doi.org/10. 1191/1352458503ms965oa

Monvoisin A, Alva JA, Hofmann JJ, Zovein AC, Lane TF, IruelaArispe ML (2006) VE-cadherin-CreERT2 transgenic mouse: a model for inducible recombination in the endothelium. Dev Dyn 235:3413-3422. https://doi.org/10.1002/dvdy.20982

Muoio V, Persson PB, Sendeski MM (2014) The neurovascular unitconcept review. Acta Physiol (Oxf) 210:790-798. https://doi.org/ 10.1111/apha. 12250

Nakagawa S, Castro V, Toborek M (2012) Infection of human pericytes by HIV-1 disrupts the integrity of the blood-brain barrier. J Cell Mol Med 16:2950-2957. https://doi.org/10.1111/j.1582-4934. 2012.01622.x

Nikolakopoulou AM, Zhao Z, Montagne A, Zlokovic BV (2017) Regional early and progressive loss of brain pericytes but not vascular smooth muscle cells in adult mice with disrupted platelet-derived growth factor receptor-beta signaling. PLoS One 12:e0176225. https://doi.org/10.1371/journal.pone.0176225

Nikolakopoulou AM et al (2019) Pericyte loss leads to circulatory failure and pleiotrophin depletion causing neuron loss. Nat Neurosci 22:1089-1098. https://doi.org/10.1038/ s41593-019-0434-Z

Nodomi S et al (2016) CD146 is a novel marker for highly tumorigenic cells and a potential therapeutic target in malignant rhabdoid tumor. Oncogene 35:5317-5327. https://doi.org/10.1038/onc. 2016.72

Nourshargh S, Krombach F, Dejana E (2006) The role of JAM-A and PECAM-1 in modulating leukocyte infiltration in inflamed and ischemic tissues. J Leukoc Biol 80:714-718. https://doi.org/10. 1189/jlb.1105645

Okabe K et al (2014) Neurons limit angiogenesis by titrating VEGF in retina. Cell 159:584-596. https://doi.org/10.1016/j.cell.2014. 09.025

Osborn L, Hession C, Tizard R, Vassallo C, Luhowskyj S, Chi-Rosso G, Lobb R (1989) Direct expression cloning of vascular cell adhesion molecule 1 , a cytokine-induced endothelial protein that binds to lymphocytes. Cell 59:1203-1211. https://doi.org/ 10.1016/0092-8674(89)90775-7

Osborne O, Peyravian N, Nair M, Daunert S, Toborek M (2020) The paradox of HIV blood-brain barrier penetrance and antiretroviral drug delivery deficiencies. Trends Neurosci 43:695-708. https:// doi.org/10.1016/j.tins.2020.06.007

Osman I, Wang L, Hu G, Zheng Z, Zhou J (2020) GFAP (glial fibrillary acidic protein)-positive progenitor cells contribute to the 
development of vascular smooth muscle cells and endothelial cells-brief report. Arterioscler Thromb Vasc Biol 40:12311238. https://doi.org/10.1161/ATVBAHA.120.314078

Ozerdem U, Grako KA, Dahlin-Huppe K, Monosov E, Stallcup WB (2001) NG2 proteoglycan is expressed exclusively by mural cells during vascular morphogenesis. Dev Dyn 222:218-227. https:// doi.org/10.1002/dvdy.1200

Park YM, Chun H, Shin JI, Lee CJ (2018) Astrocyte specificity and coverage of hGFAP-CreERT2 [Tg(GFAP-Cre/ERT2)13Kdmc] mouse line in various brain regions. Exp Neurobiol 27:508-525. https://doi.org/10.5607/en.2018.27.6.508

Parkin GM, Udawela M, Gibbons A, Dean B (2018) Glutamate transporters, EAAT1 and EAAT2, are potentially important in the pathophysiology and treatment of schizophrenia and affective disorders. World J Psychiatry 8:51-63. https://doi.org/10.5498/ wjp.v8.i2.51

Patenaude A et al (2015) A novel population of local pericyte precursor cells in tumor stroma that require Notch signaling for differentiation. Microvasc Res 101:38-47. https://doi.org/10.1016/j.mvr. 2015.05.004

Payne S, De Val S, Neal A (2018) Endothelial-specific Cre mouse models. Arterioscler Thromb Vasc Biol 38:2550-2561. https:// doi.org/10.1161/ATVBAHA.118.309669

Piller V, Piller F, Cartron JP (1990) Comparison of the carbohydratebinding specificities of seven $\mathrm{N}$-acetyl-D-galactosamine-recognizing lectins. Eur J Biochem 191:461-466. https://doi.org/10. 1111/j.1432-1033.1990.tb19144.x

Pusztaszeri MP, Seelentag W, Bosman FT (2006) Immunohistochemical expression of endothelial markers CD31, CD34, von Willebrand factor, and Fli-1 in normal human tissues. J Histochem Cytochem 54:385-395. https://doi.org/10.1369/jhc. 4A6514.2005

Raponi E, Agenes F, Delphin C, Assard N, Baudier J, Legraverend C, Deloulme JC (2007) S100B expression defines a state in which GFAP-expressing cells lose their neural stem cell potential and acquire a more mature developmental stage. Glia 55:165-177. https://doi.org/10.1002/glia.20445

Robertson RT, Levine ST, Haynes SM, Gutierrez P, Baratta JL, Tan Z, Longmuir KJ (2015) Use of labeled tomato lectin for imaging vasculature structures. Histochem Cell Biol 143:225-234. https://doi.org/10.1007/s00418-014-1301-3

Rosello-Diez A, Madisen L, Bastide S, Zeng H, Joyner AL (2018) Cell-nonautonomous local and systemic responses to cell arrest enable long-bone catch-up growth in developing mice. PLoS Biol 16:e2005086. https://doi.org/10.1371/journal.pbio.20050 86

Rowitch DH, Kriegstein AR (2010) Developmental genetics of vertebrate glial-cell specification. Nature 468:214-222. https://doi. org/10.1038/nature09611

Russell SJ, Peng KW (2007) Viruses as anticancer drugs. Trends Pharmacol Sci 28:326-333. https://doi.org/10.1016/j.tips.2007. 05.005

Saraiva J, Nobre RJ, Pereira de Almeida L (2016) Gene therapy for the CNS using AAVs: the impact of systemic delivery by AAV9. J Control Release 241:94-109. https://doi.org/10.1016/j.jconrel. 2016.09.011

Sato TN et al (1995) Distinct roles of the receptor tyrosine kinases Tie-1 and Tie-2 in blood vessel formation. Nature 376:70-74. https://doi.org/10.1038/376070a0

Satoh J, Kino Y, Asahina N, Takitani M, Miyoshi J, Ishida T, Saito Y (2016) TMEM119 marks a subset of microglia in the human brain. Neuropathology 36:39-49. https://doi.org/10.1111/neup. 12235

Shih IM (1999) The role of CD146 (Mel-CAM) in biology and pathology. J Pathol 189:4-11. https://doi.org/10.1002/(SICI) 10969896(199909)189:1\%3c4::AID-PATH332\%3e3.0.CO;2-P
Sidney LE, Branch MJ, Dunphy SE, Dua HS, Hopkinson A (2014) Concise review: evidence for CD34 as a common marker for diverse progenitors. Stem Cells 32:1380-1389. https://doi.org/ $10.1002 /$ stem. 1661

Smith AM, Dragunow M (2014) The human side of microglia. Trends Neurosci 37:125-135. https://doi.org/10.1016/j.tins.2013.12.001

Smolkova O, Zavadka A, Bankston P, Lutsyk A (2001) Cellular heterogeneity of rat vascular endothelium as detected by HPA and GS I lectin-gold probes. Med Sci Monit 7:659-668

Smyth LCD, Rustenhoven J, Scotter EL, Schweder P, Faull RLM, Park TIH, Dragunow M (2018) Markers for human brain pericytes and smooth muscle cells. J Chem Neuroanat 92:48-60. https://doi. org/10.1016/j.jchemneu.2018.06.001

Sofroniew MV, Vinters HV (2010) Astrocytes: biology and pathology. Acta Neuropathol 119:7-35. https://doi.org/10.1007/ s00401-009-0619-8

Stallcup WB (2002) The NG2 proteoglycan: past insights and future prospects. J Neurocytol 31:423-435. https://doi.org/10.1023/a: 1025731428581

Steliga A, Kowianski P, Czuba E, Waskow M, Morys J, Lietzau G (2020) Neurovascular unit as a source of ischemic stroke biomarkers-limitations of experimental studies and perspectives for clinical application. Transl Stroke Res 11:553-579. https:// doi.org/10.1007/s12975-019-00744-5

Sweeney MD, Ayyadurai S, Zlokovic BV (2016) Pericytes of the neurovascular unit: key functions and signaling pathways. Nat Neurosci 19:771-783. https://doi.org/10.1038/nn.4288

Tabata H (2015) Diverse subtypes of astrocytes and their development during corticogenesis. Front Neurosci 9:114. https://doi. org/10.3389/fnins.2015.00114

Tang Y, Harrington A, Yang X, Friesel RE, Liaw L (2010) The contribution of the Tie2+ lineage to primitive and definitive hematopoietic cells. Genesis 48:563-567. https://doi.org/10. $1002 /$ dvg.20654

Thurn KT et al (2007) Nanoparticles for applications in cellular imaging. Nanoscale Res Lett 2:430-441. https://doi.org/10. 1007/s11671-007-9081-5

Vasile F, Dossi E, Rouach N (2017) Human astrocytes: structure and functions in the healthy brain. Brain Struct Funct 222:20172029. https://doi.org/10.1007/s00429-017-1383-5

Vestweber D (2008) VE-cadherin: the major endothelial adhesion molecule controlling cellular junctions and blood vessel formation. Arterioscler Thromb Vasc Biol 28:223-232. https://doi. org/10.1161/ATVBAHA.107.158014

Wang Z, Yan X (2013) CD146, a multi-functional molecule beyond adhesion. Cancer Lett 330:150-162. https://doi.org/10.1016/j. canlet.2012.11.049

Wang Y et al (2010) Ephrin-B2 controls VEGF-induced angiogenesis and lymphangiogenesis. Nature 465:483-486. https://doi.org/ 10.1038/nature09002

Wieghofer P, Prinz M (2016) Genetic manipulation of microglia during brain development and disease. Biochim Biophys Acta 1862:299-309. https://doi.org/10.1016/j.bbadis.2015.09.019

Winchenbach J, Duking T, Berghoff SA, Stumpf SK, Hulsmann S, Nave KA, Saher G (2016) Inducible targeting of CNS astrocytes in Aldh111-CreERT2 BAC transgenic mice. F1000Res 5:2934. https://doi.org/10.12688/f1000research.10509.1

Wosik K et al (2007) Angiotensin II controls occludin function and is required for blood brain barrier maintenance: relevance to multiple sclerosis. J Neurosci 27:9032-9042. https://doi.org/ 10.1523/JNEUROSCI.2088-07.2007

Yamaguchi S, Ito S, Masuda T, Couraud PO, Ohtsuki S (2020) Novel cyclic peptides facilitating transcellular blood-brain barrier transport of macromolecules in vitro and in vivo. J Control Release 321:744-755. https://doi.org/10.1016/j.jconrel.2020. 03.001 
Yamazaki T et al (2017) Tissue myeloid progenitors differentiate into pericytes through TGF-beta signaling in developing skin vasculature. Cell Rep 18:2991-3004. https://doi.org/10.1016/j. celrep.2017.02.069

Yanagida K et al (2017) Size-selective opening of the blood-brain barrier by targeting endothelial sphingosine 1-phosphate receptor 1. Proc Natl Acad Sci USA 114:4531-4536. https://doi.org/ 10.1073/pnas.1618659114

Yoon H, Walters G, Paulsen AR, Scarisbrick IA (2017) Astrocyte heterogeneity across the brain and spinal cord occurs developmentally, in adulthood and in response to demyelination. PLoS One 12:e0180697. https://doi.org/10.1371/journal.pone. 0180697

Zarkada G, Heinolainen K, Makinen T, Kubota Y, Alitalo K (2015) VEGFR3 does not sustain retinal angiogenesis without VEGFR2. Proc Natl Acad Sci USA 112:761-766. https://doi.org/10.1073/ pnas. 1423278112

Zhang J, Jiao J (2015) Molecular biomarkers for embryonic and adult neural stem cell and neurogenesis. Biomed Res Int 2015:727542. https://doi.org/10.1155/2015/727542

Zhang Z, Ma Z, Zou W, Guo H, Liu M, Ma Y, Zhang L (2019) The appropriate marker for astrocytes: comparing the distribution and expression of three astrocytic markers in different mouse cerebral regions. Biomed Res Int 2019:9605265. https://doi.org/10.1155/ 2019/9605265

Zheng Z, Chopp M, Chen J (2020) Multifaceted roles of pericytes in central nervous system homeostasis and disease. J Cereb Blood Flow Metab 40:1381-1401. https://doi.org/10.1177/0271678X20 911331

Zhou Y, Peng Z, Seven ES, Leblanc RM (2018) Crossing the bloodbrain barrier with nanoparticles. J Control Release 270:290-303. https://doi.org/10.1016/j.jconrel.2017.12.015

Zhuo L, Theis M, Alvarez-Maya I, Brenner M, Willecke K, Messing A (2001) hGFAP-cre transgenic mice for manipulation of glial and neuronal function in vivo. Genesis 31:85-94. https://doi.org/ 10.1002 /gene. 10008

Zlokovic BV (2008) The blood-brain barrier in health and chronic neurodegenerative disorders. Neuron 57:178-201. https://doi.org/ 10.1016/j.neuron.2008.01.003

Zlokovic BV (2010) Neurodegeneration and the neurovascular unit. Nat Med 16:1370-1371. https://doi.org/10.1038/nm1210-1370

Publisher's Note Springer Nature remains neutral with regard to jurisdictional claims in published maps and institutional affiliations. 